\title{
Adding Low-Dose Antidepressants to Interferon Alpha Treatment for Chronic Hepatitis C Improved Psychiatric Tolerability in a Patient with Schizoaffective Psychosis
}

\author{
$\begin{array}{llll}\text { M. Schäfer } & \text { F. Schmidta,b } & \text { B. Amann } & \\ & & \text { S. Schlösser } & \text { K. Loeschke } \\ & \end{array}$ \\ H. Grunze ${ }^{a}$ \\ aDepartment of Psychiatry and 'Department of Gastroenterology, Klinikum Innenstadt, \\ Ludwig-Maximilians-University, Munich, Germany
}

\section{Key Words}

Interferon alpha · Psychosis · Antidepressants · Side

effects $\cdot$ Serotonin suppose that antidepressants may prevent changes in serotonergic or noradrenergic neurotransmission caused by IFN- $\alpha$.

Copyright $@ 2000$ S. Karger AG, Basel

\begin{abstract}
Treatment of chronic hepatitis $\mathrm{C}$ with interferon alpha (IFN- $\alpha$ ) is relatively contraindicated in patients with psychiatric disorders because of possible severe psychiatric side effects. We report on a case of a female patient with a chronic schizoaffective psychosis, who was treated for 3 months with $3 \times 3$ mio IE IFN- $\alpha$ s.c./week because of a chronic hepatitis $C$ (genotype $1 \mathrm{~b}$ ). Psychosis was stable with flupentixol monotherapy. After 2 months, she developed a severe depressive syndrome which lead to suicidal ideation. Until this time, she was without any antidepressive medication. Depressive symptoms disappeared after interferon therapy was stopped. Under prophylactic treatment with low-dose trimipramine $(50 \mathrm{mg}$ ) or nefazodone $(200 \mathrm{mg} /$ day) therapy with IFN- $\alpha 3 \times$ 3 mio IE/week was re-established after several months and again 2 years later adding ribavirin $1200 \mathrm{mg} / \mathrm{day}$, a virustaticum. In contrast to the symptoms during monotherapy with IFN- $\alpha$, during the time of both combination treatments, no psychiatric side effects occurred. While for ribavirin antidepressant effects are not known, we
\end{abstract}

\begin{tabular}{ll}
\hline KARGER & ( 2000 S. Karger AG, Basel \\
0302-282X/00/0425-0043\$17.50/0 \\
$\begin{array}{l}\text { Fax +4161306 1234 } \\
\text { www.karger.com }\end{array}$ & $\begin{array}{l}\text { Accessible online at: } \\
\text { www.karger.com/journals/nps }\end{array}$
\end{tabular}

\section{Introduction}

Interferon-alpha (IFN- $\alpha$ ) is an important part of the natural immune system with antiviral, antitumor and immunoregulatory properties. Recently there has been an extensive therapeutic use of interferons in viral infection disorders, including hepatitis $\mathrm{B}$ and $\mathrm{C}$, neoplastic disorders, myeloproliferative and rheumatic disorders [1]. The treatment duration differs between months and years. Besides several possible internal complications, psychiatric side effects like affective, psychotic or delirious syndromes associated with IFN- $\alpha$ therapy often limit the otherwise effective immunotherapy [2-4]. Worldwide, 100 million people are infected with the hepatitis $\mathrm{C}$ virus and $70 \%$ of those develop a chronic hepatitis C. Most of them need treatment to avoid complications such as liver cirrhosis, which occurs in 15-20\% [5]. The only effective treatment has been IFN- $\alpha$ so far. But in psychiatric patients, treatment with IFN- $\alpha$ is still considered as contraindicated because of the hypothetical increased risk for

Dr. med. Martin Schäfer

Department of Psychiatry, Ludwig-Maximilians-University of Munich

Nussbaumstrasse 7, D-80336 Munich (Germany)

Tel. +49 8951605721, Fax +49 8951605727

E-Mail martin.schaefer@psy.med.uni-muenchen.de 
Fig. 1. Psychiatric rating scales during treatment with IFN- $\alpha$ and ribavirin. GAF = Global Assessment of Functioning Scale; SDS = Self-Rating Depression Scale; MADRS = Montgomery-Asberg Depression Scale; BPRS = Brief Psychiatric Rating Scale; STAIX1 = State-Trait-Anxiety Inventory.

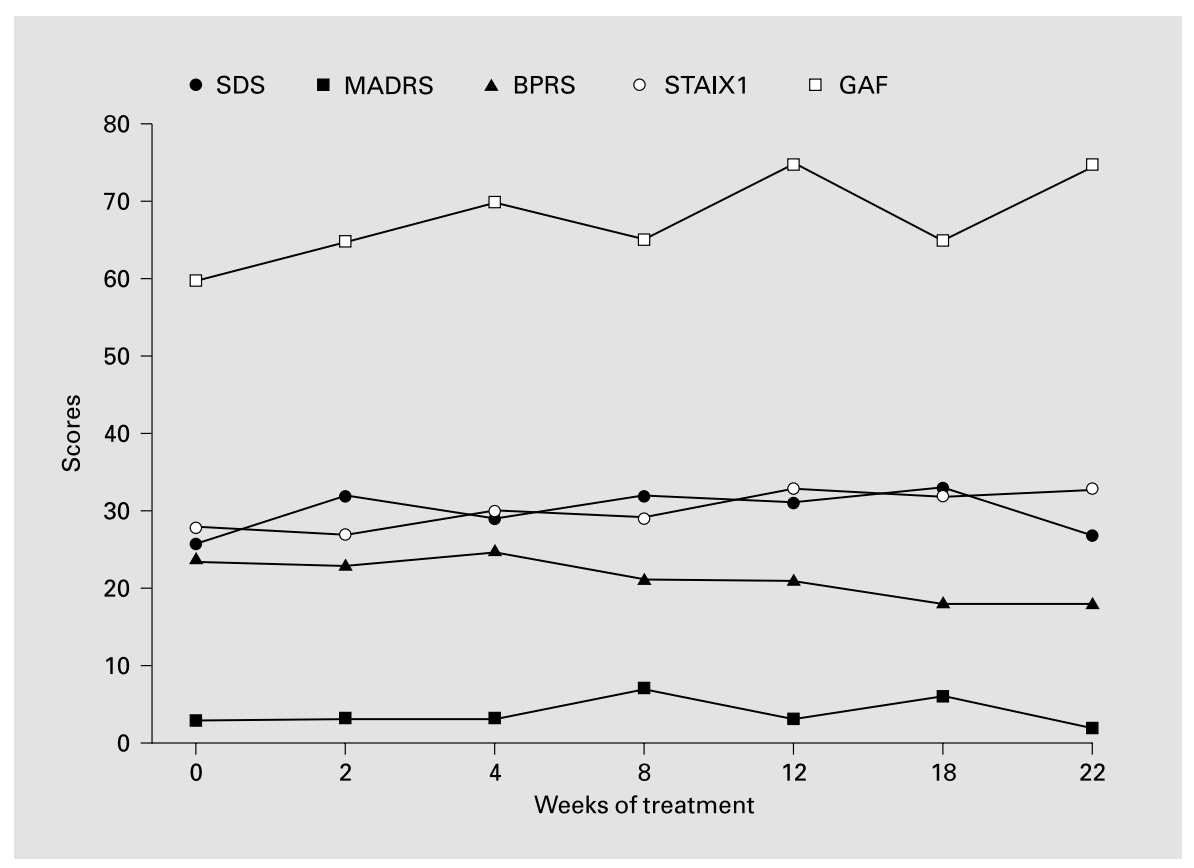

the development of depressive and suicidal syndromes [6]. Antidepressants were shown to be sometimes helpful in the treatment of depressive syndromes associated with IFN- $\alpha$ [7] and may save patients from the necessary discontinuation of therapy. But it is not yet known if antidepressants may have a protective effect and if retreatment with IFN- $\alpha$ is possible in psychiatric patients who developed severe depressive side effects during earlier IFN- $\alpha$ treatment. The presented prospective and clinically extensively characterized case of a 'high-risk' patient with schizoaffective disorder gives evidence for the efficacy of antidepressants even in low dose in the prevention of IFN- $\alpha$-associated depressive syndromes.

\section{Case Report}

The 40-year-old female patient was treated with IFN- $\alpha$ because of a chronic hepatitis C. Hepatitis C was diagnosed in 1996 with genotype $1 \mathrm{~b}$, which is known to be associated with a bad prognosis and bad response to monotherapeutic treatment with IFN- $\alpha$. After a suicide attempt in 1986, the patient was diagnosed as having schizoaffective disorder and has been treated continuously since 1995 with flupentixol monotherapy, occasionally in combination with trimipramine or amitriptyline up to $75 \mathrm{mg} /$ day. This led to an amelioration of psychotic symptoms for more than 5 years, whereas depressive symptoms intermittently reappeared.

In 1996, monotherapeutic treatment of hepatitis C with IFN- $\alpha$ $3 \times 3$ mio IE/week was initiated under continuous psychiatric care. At this time, the patient was under flupentixol monotherapy and without psychotic or depressive symptoms. After 2 months of IFN- $\alpha$ treatment, she developed a severe depressive syndrome with depressed mood, agitation, sleeping disturbance, anxiety and suicidal ideation. IFN- $\alpha$ was stopped, and the patient was consecutively put on trimipramine $(75 \mathrm{mg} /$ day $)$ and later amitriptyline $(50 \mathrm{mg} /$ day $)$. One week after discontinuation of IFN- $\alpha$, proneness to suicide was diminished, followed by the amelioration of the other depressive symptoms 2 weeks later.

In 1997 , a combination therapy with ribavirin $(1,000 \mathrm{mg} /$ day $)$ and IFN- $\alpha 3 \times 3$ mio IE/week was started while on psychiatric treatment with flupentixol ( $1 \mathrm{ml} 2 \%$ every 3 weeks) and trimipramine (50 mg/day). Especially in patients with hepatitis virus genotype 1 , response to combination treatment is better compared to monotherapy. Neither psychiatric syndromes nor other severe side effects were noticed by the psychiatrist or by the patient herself. Treatment was stopped after 4 months because the PCR for hepatitis $\mathrm{C}$ virus was still positive, whereas liver enzymes were normalized (partial response).

In 1998, the patient wished to start again on a combination treatment with ribavirin $(1,000 \mathrm{mg} /$ day $)$ and IFN- $\alpha 3 \times 3$ mio IE/week for 6 months. A special study design for treatment of psychiatric patients with chronic hepatitis $\mathrm{C}$ was applied. She was treated continuously with flupentixol and nefazodone in a low dose (100 mg/day). Under this medication, no depressive symptoms were noticed. Again, she did not complain about any severe psychiatric side effects during combination treatment of hepatitis C. Prospective psychiatric ratings like the BPRS (Brief Psychiatric Rating Scale) or the Montgomery-Asberg Depression Scale, as well as self-rating instruments for anxiety and depressive symptoms (STAIX1, SDS) showed no relevant negative changes (fig. 1). However, the PCR for hepatitis C virus detection was still positive after 6 months, and the patient was considered as not responding to this treatment. 


\section{Discussion}

Comparing combination treatment with IFN- $\alpha$ monotherapy, the patient experienced aggressive feelings, anxiety, lack of drive, irritability, depressive mood, sleeping disturbance, loss of interests, ambivalence, disturbance of concentration, rumination, suicidal thoughts, mood instability and inner restlessness only during monotherapy. Only drowsiness was described as noteworthy during combination treatment. The patient was not in a depressive mood before the IFN- $\alpha$ treatments. In contrast to the monotherapeutic regime with IFN- $\alpha$ in 1996, the patient was under continuous antidepressive treatment during both combination therapies. Serotonergic-acting antidepressants have recently been shown to be effective in preventing psychiatric side effects with high-dose interferon treatment for malignant melanoma given before starting the IFN- $\alpha$ treatment [8]. Accordingly, antidepressant medication with trimipramine or nefazodone possibly prevented depressive symptoms in our patient. However, the therapeutic dose recommended for nefazodone is 400-600 mg/day. Our patient only received a low-dose treatment for both antidepressants used. Interestingly, besides depressive symptoms, most patients develop irritability or aggression under treatment with IFN- $\alpha$. Impulsive, aggressive behavior and depression are thought to be connected to serotonergic dysfunction. In fact, cytokines like IL- 1 and IL-6, which are influenced by IFN- $\alpha$, are known to alter the cerebral metabolism of noradrenaline and serotonin [9]. IFN- $\alpha$ affects low-affinity 5-HT1A receptor sites in rats [10] and increases levels of serotonin transporter mRNA [11].

Another possibility could be a better tolerability of the combination therapy with IFN- $\alpha$ and ribavirin. Even if large clinical studies suggest that the prevalence of severe psychiatric side effects with suicidal ideation is similar for the patients treated with IFN- $\alpha 2 b$ and ribavirin compared to monotherapy with IFN- $\alpha 2$ b (3.6 vs. $2.2 \%$ ), they were done without valid psychiatric ratings $[12,13]$. If it holds true that adding ribavirin reduces psychiatric side effects of IFN- $\alpha$ in selected patients, the underlying mechanism remains still unclear.

In conclusion, pretreatment with low-dose antidepressants may be effective in preventing depression as a serotonergic side effect of IFN- $\alpha$ treatment. Further studies to evaluate the psychiatric tolerability of the new combination treatment with IFN- $\alpha$ and ribavirin for chronic hepatitis $\mathrm{C}$ are needed. To our knowledge, there is no justifiable reason to exclude psychiatric patients from effective treatment for chronic hepatitis $\mathrm{C}$, even in cases of earlier side effects [14].

\section{References}

1 Cirelli R,Tyring SK: Major therapeutic uses of interferons. Clin Immunother 1995;3:27-87.

2 Janssen HLA, Brouwer JT, van der Mast RC, Schalm SW: Suicide associated with alphainterferon therapy for chronic viral hepatitis. J Hepatol 1994;21:241-243.

3 Renault FP, Hoofnagle JH: Side effects of alpha interferon. Semin Liver Dis 1989;9:273277.

4 Renault FP, Hoofnagle JH, Park Y, Mullen KD, Peters M, Jones DB, Rustgi V, Jones EA: Psychiatric complications of long-term Interferon alpha therapy. Arch Intern Med 1987; 147:1577-1580.

5 Alter MJ: Epidemiology of hepatitis C. Hepatology 1997;26:62-65.

6 McDonald EM, Mann AH, Thomas HC: Interferons as mediators of psychiatric morbidity. Lancet 1987;2:1175.
7 Levenson JL, Fallon HJ: Fluoxetine treatment of depression caused by interferon-alpha. Am J Gastroenterol 1993;88:760-761.

8 Miller A, Musselman D, Penna S, Su C, Pearce B, Nemeroff C: Pretreatment with the antidepressant paroxetine prevents cytokine-induced depression during IFN-alpha therapy for malignant melanoma. Neuroimmunomodulation 1999;6:237.

9 Dunn AJ, Wang J, Ando T: Effects of cytokines on cerebral neurotransmission. Comparison with the effect of stress. Adv Exp Med Biol 1999;461:117-127.

10 Abe S, Hori T, Suzuki T, Baba A, Shiraishi H, Yamamoto T: Effects of chronic administration of interferon alpha $\mathrm{A} / \mathrm{D}$ on serotonergic receptors in rat brain. Neurochem Res 1999; 24:359-363.

11 Morikawa O, Sakai N, Obara H, Saito N: Effects of interferon-alpha, interferon-gamma and CAMP on the transcriptional regulation of the serotonin transporter. Eur J Pharmacol 1998;22:317-324
12 McHutchison JG, Gordon SC, Schiff ER, Shiffman ML, Lee WM, Rustgi VK, et al: Interferon alpha-2b alone or in combination with Ribavirin as initial treatment for chronic hepatitis C. Hepatitis Interventional Therapy Group. N Engl J Med 1998;339:1485-1492.

13 Poynard T, Marcellin P, See S, Niederau C, Minuk GS, Ideo G, Bain V, Heathcote J, Zeuzem S, Trepo C, Albrecht J: Randomised trial of interferon- $\alpha 2 \mathrm{~b}$ plus ribavirin for 48 weeks or for 24 weeks versus interferon- $\alpha 2 \mathrm{~b}$ plus placebo for 48 weeks for treatment of chronic infection with hepatitis $\mathrm{C}$ virus. International Hepatitis Interventional Therapy Group (IHIT). Lancet 1998;352:1426-1432.

14 Pariante CM, Orru MG, Baita A, Farci MG, Carpiniello B: Treatment with interferon-alpha in patients with chronic hepatitis and mood or anxiety disorders. Lancet 1999;354:131-132. 